\title{
THE SOCIAL SIDE OF SANCTIONS: PERSONAL AND SOCIAL NORMS AS MODERATORS OF DETERRENCE
}

\author{
Michael Wenzel
}

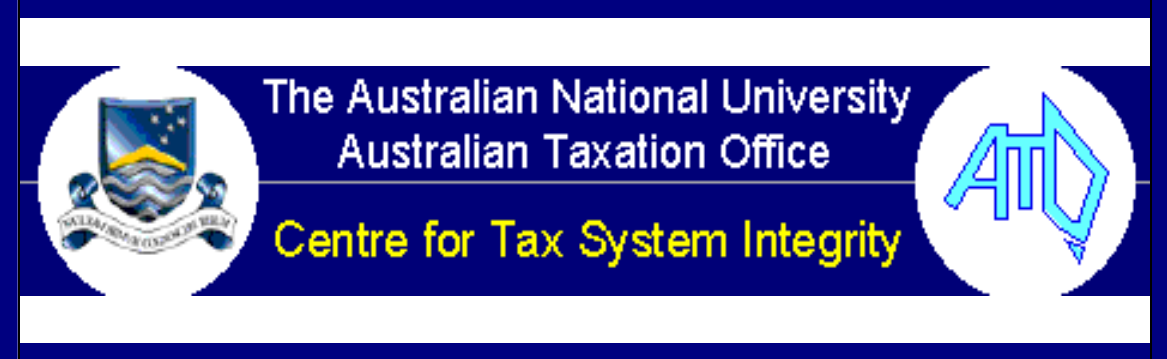

WORKING PAPER No 34

October 2002 


\title{
THE SOCIAL SIDE OF SANCTIONS: PERSONAL AND SOCIAL NORMS AS MODERATORS OF DETERRENCE
}

\author{
Michael Wenzel
}

\author{
Centre for Tax System Integrity \\ Research School of Social Sciences \\ Australian National University \\ Canberra, ACT, 0200 \\ ISBN 0642768331 \\ ISSN 1444-8211
}

\section{WORKING PAPER No 34 \\ October 2002}


(C) Centre for Tax System Integrity, Research School of Social Sciences, Australian National University 2002

(C) Commonwealth of Australia 2002

National Library of Australia

Cataloguing-in-Publication data:

Wenzel, M. 1966 -

The social side of sanctions: Personal and social norms as moderators of deterrence.

Bibliography.

ISBN 0642768331.

1. Constitutional law - Australia - Citizen participation.

I. Centre for Tax System Integrity. II. Title. (Series :

Working paper (Centre for Tax System Integrity); no. 34).

342.9402

If you would like to make any comments on this working paper please contact the author directly within 90 days of publication.

\section{Disclaimer}

This article has been written as part of a series of publications issued from the Centre for Tax System Integrity. The views contained in this article are representative of the author only. The publishing of this article does not constitute an endorsement of or any other expression of opinion by the Australian National University or the Commissioner of Taxation of the author's opinion. The Australian National University and the Commissioner of Taxation do not accept any loss, damage or injury howsoever arising that may result from this article. This article does not constitute a public or private ruling within the meaning of the Taxation Administration Act 1953, nor is it an advance opinion of the Commissioner of Taxation. 


\section{THE CENTRE FOR TAX SYSTEM INTEGRITY WORKING PAPERS}

The Centre for Tax System Integrity (CTSI) is a specialised research unit set up as a partnership between the Australian National University (ANU) and the Australian Taxation Office (Tax Office) to extend our understanding of how and why cooperation and contestation occur within the tax system.

This series of working papers is designed to bring the research of the Centre for Tax System Integrity to as wide an audience as possible and to promote discussion among researchers, academics and practitioners both nationally and internationally on taxation compliance.

The working papers are selected with three criteria in mind: (1) to share knowledge, experience and preliminary findings from research projects; (2) to provide an outlet for policy focused research and discussion papers; and (3) to give ready access to previews of papers destined for publication in academic journals, edited collections, or research monographs. 


\begin{abstract}
This study investigated how personal ethics and social norms interact with deterrence in their effects on tax compliance. In line with earlier research, it is argued and shown that strong personal tax ethics reduce effects of deterrence. Strong tax ethics basically exclude tax evasion from one's behavioural options and no deterrence is required to maintain tax honesty. Such personal ethics are partly based on social norms that are internalised in one's own ethical make-up. In contrast, social norms that are not internalised (for example, because one does not identify with the group holding these norms) can enhance effects of deterrence, because they add social costs to the material costs of sanctions, such as reputation threat and stigma.
\end{abstract}

The study was based on data from The Community Hopes, Fears, and Actions Survey (Braithwaite, 2001) involving 2040 Australian participants. It investigated three different self-reported acts of tax evasion, namely pay income underreporting, non-pay income underreporting and exaggerations of deductions; and three aspects of deterrence incorporating legal sanctions, namely the perceived probability of detection, the perceived probability of legal consequences and the perceived severity of the consequences. Although the importance of the three deterrence aspects varied somewhat between the three forms of evasion, perceived sanction severity was overall the most relevant aspect. The results showed that personal taxpaying ethics were negatively related to tax evasion, while social norms (beyond those internalised as personal ethics) had no direct effect. Personal ethics moderated the deterring effects of legal sanctions; deterrence was stronger when people's ethics were only weakly opposed to tax evasion. Social norms moderated the effects of deterrence when personal norms were controlled and identification as Australians was weak: the deterring effects of legal sanctions were greater when social norms were strongly opposed to tax cheating.

The study thus provides a strong argument for the investment of much regulatory effort in the establishment of supportive taxpaying norms and culture. In line with the compliance model of the Australian Taxation Office, it would be important to nurture personal norms of tax honesty, because this would make any more costly and potentially alienating regulatory activities unnecessary. However, when personal norms fail and regulatory measures would escalate to more stringent levels of enforcement, the effects of deterrence would be greatly supported by a positive tax paying culture; again the nurture of supportive norms is paramount. Finally, by building strong identification with one's community and representative institutions as well as furthering positive taxpaying norms, tax regulators would move taxpayers down to the cooperative base of the compliance model's regulatory pyramid. 


\section{The Social Side of Sanctions: Personal and Social Norms as Moderators of Deterrence}

Michael Wenzel

In theory and practice, the most common approach to explain taxpaying behaviour is the rational actor approach and its corresponding regulatory strategy of deterrence. However, while there is supportive, although not always consistent, empirical evidence for deterrence effects on tax compliance (see Fischer et al., 1992; Varma \& Doob, 1998), there has been growing evidence that decisions to evade tax are also affected by moral considerations and social factors (for example, Alm et al., 1999; DeJuan et al., 1994). Beyond the issue of tax compliance, criminal justice research in recent years has seen a new emphasis on social norms and social meaning (see Harcourt, 2000; McAdams, 1997). In a similar vein, the present paper investigates personal and social norms, internalised and externally attributed prescriptions, with regard to their roles in the deterrence process, in order to understand better the limitations and force of this regulatory approach.

\section{Deterrence and Tax Compliance}

The rational-actor approach sees taxpayers as outcome-maximising information processors who in a state of uncertainty choose between two options. The first, being compliant, and incurring a certain loss in terms of the taxes paid. Or secondly, evading taxes with the chance of either a relative material gain if the evasion is undetected or an even greater material loss if the evasion is detected and penalised (for example, Allingham \& Sandmo, 1972). Hence, taxpayers should be deterred from tax evasion when they perceive the chance that their evasion would be detected to be high and the consequences and penalties to be severe and costly. Detection probability and severity of sanctions, or, more specifically, perceptions thereof (perceptual deterrence; see Paternoster, 1987; Williams \& Hawkins, 1986), should thus affect taxpaying decisions. In fact, according to the rational actor approach, detection probability and sanction severity should interact in their effects, as it is their product that defines the expected value and contributes to the expected (dis)utility of tax evasion. The rational actor prediction is that a certain probability of sanction $\mathrm{X}$ will be equally deterring to twice that probability of half $\mathrm{X}$. While statistical models may be specified on theoretical grounds as focusing on the interactive effect 
(Grasmick \& Bursik, 1990; Wenzel, 2002a), there is empirical evidence that detection probability and sanction severity can have additive effects and people focus on one dimension or the other (Carroll, 1978).

There is overall supportive evidence for deterrence effects on tax compliance, notwithstanding the limitations of the various methodological approaches applied (see Andreoni et al., 1998; Franzoni, 2000; Fischer et al. 1992). Specifically, evidence of the effects of audit or detection probability has been found in regression analyses of actual taxpayer data (Witte \& Woodbury, 1985), experimental studies (Alm et al., 1992, 1995; Webley, 1987; Webley \& Halstead, 1986), and survey research (Kinsey \& Grasmick, 1993; Mason \& Calvin, 1978; Sheffrin \& Triest, 1992; Varma \& Doob, 1998), while there have been also some inconsistent findings (Dubin et al., 1987; Dubin \& Wilde, 1988). Similarly, there is evidence for the positive effects of sanction severity on tax compliance (Alm et al., 1995; DeJuan et al., 1994; Friedland et al., 1978), but findings are here more inconsistent (Elffers et al., 1987; Varma \& Doob, 1998; Webley \& Halstead, 1986).

Importantly, however, it has increasingly been argued that research needs to incorporate noneconomic factors such as norms, fairness and morality in order to better understand tax compliance, rather than merely economic self-interest with which the rational actor approach is preoccupied (Alm et al., 1995; DeJuan et al., 1994; Cowell, 1992; Falkinger, 1995; Schmölders, 1970; Vogel, 1974; Wallschutzky, 1984). In fact, social factors may substantially impact on and qualify the deterrence process. For instance, Scott and Grasmick (1981) reported survey findings showing that legal sanctions had a greater deterrence effect on tax evasion for respondents who perceived the tax system as unjust and were thus presumably more motivated to evade tax. Likewise, Wenzel (2002a) provided evidence that perceived deterrence was less effective for respondents who identified strongly with their nation and were thus presumably less motivated by individual self-interest than the collective good.

The present paper focuses on norms in their relation to deterrence. Tax compliance research has provided evidence for two possible ways in which norms can qualify 
deterrence effects. One argument akin to that of Scott and Grasmick (1981) posits that deterrence would only be relevant and effective for taxpayers who do not have strong ethical objections against tax evasion. In contrast, taxpayers who have internalised norms against tax evasion, excluding it from their range of behavioural options, would be unaffected by deterrence variables (Carroll, 1987; see Grasmick \& Green, 1980). For example, Smith (1990) showed that perceived probability of detection had a stronger effect on self-reported underreporting of income for respondents who regarded incomeunderreporting as acceptable, while the deterrence effect was smaller for respondents who considered such tax evasion to be less acceptable. Similar findings have been reported with criminal or deviant behaviour other than tax evasion (Bachman et al., 1992; Burkett \& Ward, 1993; Paternoster \& Simpson, 1996; Simpson, 2002).

A second argument posits that deterrence effects of legal punishments of unlawful behaviour are often smaller than the inhibiting effects of social norms. Social norms could either be internalised and, as personal norms and ethical sentiments, evoke guilt or shame if one committed tax evasion. Or, social norms could be attributed to others who might express their disapproval, withhold social rewards, or sever valued relationships if one committed tax evasion. For instance, in their classic field experiment, Schwartz and Orleans (1967) used survey questions to activate in taxpayers either moral concerns against tax cheating or the prospect of legal punishments of tax evasion. They concluded that the appeal to conscience increased tax compliance more effectively (in terms of income reported) than the legal sanction threat. Grasmick and Scott (1982) used equivalent survey items measuring the anticipation of guilt, stigma, and legal punishment, respectively, and found stronger effects for guilt than the other two threats (see also Grasmick and Bursik, 1990; Scott and Grasmick, 1981). A number of other studies produced similar findings of internalised norms and tax ethics increasing tax compliance (for example, Bosco \& Mittone, 1997; Erard \& Feinstein, 1994; Hasseldine \& Kaplan, 1992; Kaplan \& Reckers, 1985; Reckers et al., 1994). 


\section{Williams and Hawkins (1986) Revisited}

In their influential critique of perceptual deterrence research, Williams and Hawkins (1986) argue however that the effects of deterrence, on the one hand, and social norms, on the other hand, not be set against each other and not be compared with each other, as if they were independent mechanisms. Findings that sanctions based on personal ethics and social norms outperform legal sanctions in their effects, or that legal sanctions lose their effect once informal sanctions are controlled for (Paternoster et al., 1983), should not be taken as simple evidence that norm-based, informal sanctions are more important than legal sanctions. This would mean to ignore the possibility that legal sanctions partly operate on the basis of social norms; it would mean to underestimate and misconceive the functions of legal sanctions.

Specifically, Williams and Hawkins (1986) differentiate between three general processes by which legal sanctions can inhibit crimes. First, there is the process of 'mere deterrence' (Andenaes, 1974) where legal sanctions in and of themselves are counter to one's individual self-interest; the prospect of punishment in terms of its immediate material or physical costs deters the criminal act. Second, there is the process of 'normative validation' (Gibbs, 1975) where legal sanctions increase the perception that the criminal act is morally wrong; via this effect on one's ethical views and internalised norms, sanctions inhibit the criminal offence. Here, legal sanctions would operate through the same processes as extralegal sanctions do. Third, there is a socially-mediated process of deterrence where legal sanctions are 'costly' due to others' reaction to one's conviction, arrest or legal punishment. People are, in their attempts to attain esteem, attachment, and even material goals, dependent on others. If others reacted negatively to one's conviction of a crime, they could stigmatise the offender and end their relationship to, or cooperation with, the offender.

The third effect of legal sanctions, what is called here socially-mediated deterrence, has not received much research attention and, according to Nagin and Paternoster (1991), little supportive evidence. For instance, Nagin and Paternoster (1991) themselves used panel self-report data on property theft and drug use among high school students. They found no, 
or at best only modest, support for an interaction between perceived probability of arrest and 'commitment costs', that is the expectation that others' reactions to one's arrest would hamper the realisation of one's goals (see Williams and Hawkins, 1986). Likewise, in a study on students' projected sexual offending, Bachman et al. (1992) did not find any evidence that perceived certainty of formal sanctions would deter more strongly when respondents expected strong social disapproval and loss of respect in case of an arrest for the offence. However, rather than rejecting Williams and Hawkins' (1986) analysis on the basis of these findings, I will take a closer look at it and offer some theoretical differentiation.

Similar to Nagin and Paternoster (1991) and Bachman et al. (1992), I argue that sociallymediated deterrence should be reflected in an interaction between variables of deterrence (for example, detection probability, sanction severity) and the perceived prescriptive norms regarding the behaviour (for example, paying one's taxes). If socially-mediated deterrence is at work, high perceived detection probability and sanction severity should deter respondents from evading tax more effectively, when they think prevailing norms oppose tax evasion and others would thus react very negatively to their conviction. Importantly, we would thus expect an interaction effect of deterrence variables and social norms that is opposite to the interaction between deterrence and personal ethics as discussed earlier. To clarify and reconcile these contrary effects, we need to distinguish between personal and social norms (Wenzel, 2002b).

Personal norms are defined here as people's own moral standards, acquired, for instance, through the internalisation of social norms (see Kelman, 1958). Internalisation is understood here as occurring through a process of self-categorisation in terms of, or identification with, the group to which people attribute the norms; the group becomes part of self, and the person feels committed to norms and values shared within the group (Turner, 1991). Social norms are defined here as moral standards attributed to a social group or collective. While these may be internalised as personal norms through selfcategorisation, part of one's social norms may remain external to the person. As an approximation, we obtain the external part of social norms when controlling statistically for personal norms. Crucially, because opposite interaction effects with deterrence are 
predicted for internalised and 'externalised' norms, we need to control for personal norms and the internalisation process if we want to find the interaction effect for social norms as it follows from Williams and Hawkins' (1986) analysis. Otherwise the interaction effects for internalised norms and 'externalised' norms could offset each other.

Note that Bachman et al. (1992) created subgroups of respondents who expected high, medium, or low social disapproval, without controlling for respondents' own moral beliefs in the creation of these groups. They found, against their prediction, significant deterrence effects for high and low disapproval groups. It could be that the high disapproval group was indeed more strongly deterred by formal sanctions (compared to the medium disapproval group) because of the reactions they expected from others. In contrast, the low disapproval group might have been more strongly deterred because their own moral standards, likely to be correlated with perceived disapproval, were also low, thus did not curtail their behavioural options and left open a rational appraisal of the costs of formal sanctions.

This is the first part of my theoretical differentiation. Internalised norms against tax evasion should delimit the effects of deterrence variables, because legal punishment becomes irrelevant when personal ethics already exclude tax evasion from one's behavioural options. However, externalised norms against tax evasion (that is, social norms while controlling for personal norms) should increase effects of deterrence, because legal sanctions imply additional, socially mediated costs that could deter the individual from acts of tax evasion. Furthermore, if it is externalised social norms that boost deterrence effects, then an interaction between social norms and legal sanctions should be more pronounced for respondents who do not identify with the social group to which they attribute the social norms, and who are thus less likely to internalise or share the group's norms. While it was said that personal taxpaying norms could be conceived as internalised social norms, and controlling for personal norms should control for the internalisation of group norms, this is probably only partly the case (Wenzel, 2002b). Personal norms can also partly reflect one's distinctive position with a reference group, characterising one's personal self in contrast to other members of one's reference group (see Turner, 1987). Hence, a clearer interaction pattern between social norms and deterrence variables should result if we considered a 
moderating effect of group identification, that is the process underlying the internalisation of norms.

\section{Summary of Hypotheses}

In line with the traditional deterrence model, it was predicted that $(\mathrm{H} 1)$ deterrence variables would be positively related to tax compliance. In the present research, I decomposed the deterrence construct into three elements: perceived probability of detection, perceived probability of consequences, and perceived severity of consequences.

In line with the existing evidence on the role of individual morality, it was predicted that (H2) the personal norm (of tax honesty) would be negatively related to tax compliance. Further, next to this main effect, the personal norm would also moderate the effects of the deterrence components: (H3) when personal norms were strong, deterrence components would have no (or weaker) effects; but when personal norms were weak, deterrence variables would be more strongly negatively related to tax noncompliance.

In contrast, social norms, beyond those statistically controlled for as personal norms, would have no significant simple effect on compliance. Being rather external to one's self, they in and of themselves would not motivate taxpayers to comply with the laws. However, when social norms are considered to be strongly against tax evasion, they may add social meaning and social costs to legal sanctions, such as shame and embarrassment in the face of a conviction of tax fraud. Hence, (H4) when social norms are weak, deterrence components would have no (or weaker) effects; but when social norms are strong, deterrence variables would be more strongly negatively related to tax noncompliance.

In line with the assumption that this is an effect of socially-mediated deterrence and social pressure due to social norms external to one's self, the interaction effect should only hold for respondents who do not identify with the collective holding these norms. Hence, (H5) when group identification is weak, social norms would have a deterring effect on taxpayers and boost deterrence components in their effect on compliance; when identification is 
strong, no deterring effect of social norms in combination with deterrence components would result.

\section{Method}

\section{Participants}

The data were taken from The Community, Hopes, Fears, and Actions Survey (Braithwaite, 2000). The self-completion questionnaire was sent to a random sample of 7754 Australian citizens drawn from the Australian electoral roll. Subtracting cases where the mail was returned to sender, addressees were deceased, and so on, 7003 questionnaires were effectively sent out (for procedural details, see Mearns \& Braithwaite, 2001). After repeated appeals for participation, 2040 respondents, or 29\%, returned their questionnaires. The response rate for this rather long questionnaire thus compares with experiences from other mail surveys on tax issues in Australia (Wallschutzky, 1984, 1996). Compared to census data, the sample proved broadly representative for the Australian population, but it tended to underrepresent people younger than 35 and overrepresent people between 40 and 65 years of age as well as those with higher education (Mearns \& Braithwaite, 2001).

However, the number of valid cases for the present analyses was further reduced by a relatively large number of missing values (for the most comprehensive analysis listwise $N$ $=1307)$. Inspection of differences between valid and missing cases, however, suggests that there were good reasons for this. Measures of tax compliance behaviour require that respondents actually fill in tax returns, while the present sample was taken from registered voters, some of whom might have no obligation to lodge tax returns. Other respondents might leave it to their partners to fill in their tax returns for them. In fact, large proportions of people aged 65 or older $(65 \%)$ and respondents with low personal income of up to A $\$ 10000$ (52\%) had missing values; together these accounted for about $60 \%$ of missing cases. Also, a higher proportion of respondents with missing cases were female (58\%). Thus, the drop-out of cases seemed to render the valid sample more representative of respondents who actually made taxpaying decisions. However, the fact that some of the survey questions addressed illegal behaviour and other sensitive issues may also have caused certain respondents to omit answers. The participants in the final sample (for the 
lowest listwise $\mathrm{N})$ were between 18 and 89 years old $(M d n=45) ; 49.9 \%$ were male, $50.1 \%$ were female.

\section{Procedure}

The questionnaire was sent to respondents with a reply-paid envelope and an accompanying letter. The letter explained the intent of the study, the researchers' relationship to the Australian Taxation Office, and guaranteed strict confidentiality of responses. An identification number on the questionnaire allowed a targeted follow-up (with reminder letters and new questionnaires) for cases where the questionnaire was not returned by a certain deadline. Excluding breaks, which were explicitly recommended at various stages of the questionnaire, respondents would have needed an estimated 1.5 hours to fill it in.

\section{Questionnaire}

\section{Tax Compliance}

Based on previous work (Wenzel, 2002a), three forms of tax evasion were distinguished: underreporting of Pay Income, underreporting of Non-Pay Income, and exaggerations of Deductions. These behaviours were measured as follows:

Pay Income: Four items measured whether or not respondents declared all their pay income: 'As far as you know, did you report all the money you earned in your 1998-99 income tax return?' $(1=$ yes, $2=n o)$; 'Have you worked for cash-in-hand payments in the last 12 months? By cash-in-hand we mean cash money that tax is not paid on.' $(1=$ yes, 2 $=n o$; reverse-coded); 'People earn income from many different sources, [...] Think about each of the sources of income listed below, and select the response that best describes your 1998-99 income tax return.' $(1=$ received none, 2 = did not declare it, $3=$ declared some, 4 = declared most, 5 = declared all; recoded into 1, 2, 2, 2, and 1, respectively): (1) salary, wages; (2) honorariums, allowances, tips, bonuses, director's fees. Scores of the four items were averaged to yield the Pay Income measure $(\alpha=0.62)$. 
Non-Pay Income: The previous question was continued for non-pay income (see Wenzel, 2002a): (3) eligible termination payments; (4) Australian government allowances like Youth Allowance, Austudy, Newstart; (5) Australian government pension, superannuation pensions, and other pensions and annuities; (6) interest; (7) dividends. Scores of the five items were averaged to yield the Non-Pay Income measure $(\alpha=0.78)$.

Deductions: Two questions addressed respondents' deduction claims: 'As far as you know, did you exaggerate the amount of deductions or rebates in your 1998-99 income tax return?' (1 = a lot, 2 = quite a bit, 3 = somewhat, 4 = a little, 5 = not at all; reverse-coded); 'Think of the deductions and rebates you claimed in your 1998-99 income tax return. Would you say you were ...' $(1=$ absolutely confident that they were all legitimate, $2=a$ bit unsure about some of them, 3 = pretty unsure about quite a lot, $4=$ haven't a clue, someone else did it; recoded into 1, 2, 2, and 2, respectively). Scores of the two items were standardised, then averaged to obtain the Deductions measure $(\alpha=0.51)$.

Tax Evasion: A summary variable comprising all three forms of taxpaying behaviour was also calculated. Scores for underreporting of Pay Income, underreporting of Non-Pay Income, and false Deduction claims were first standardised and then averaged to obtain a measure of Tax Evasion $(\alpha=0.61)$.

\section{Deterrence}

Perceived deterrence was conceptualised in line with an expectancy-by-value approach (Grasmick \& Bursik, 1990; Wenzel, 2002a) and comprised three sub-concepts: perceived Probability of Detection, perceived Probability of Consequences, and perceived Severity of Consequences. In the present research, these were treated as different subscales and investigated with regard to their separate effects. All three elements were measured in the context of two scenarios. In one scenario, respondents were asked to imagine they had been paid A $\$ 5000$ in cash for work outside their regular job and did not declare it on their income tax return. In another scenario, they were asked to imagine they had claimed A $\$ 5000$ as work deductions when the expenses had nothing to do with work. 
Probability of Detection: In each scenario, respondents were asked for the probability of getting caught: 'What do you think the chances are that you will get caught?' ( 1 = about zero $[0 \%], 2=$ about $25 \%, 3=$ about $50 \%, 4=$ about $75 \%, 5=$ almost certain $[100 \%]$ ).

Probability of Consequences: In each scenario, respondents were asked for the probabilities of certain legal consequences: 'If you did get caught, what are the chances that you would have to face the following legal consequences? (a) Taken to court + pay a substantial fine + pay the tax you owe with interest; (b) taken to court + pay the tax you owe with interest; (c) pay a substantial fine + pay the tax you owe with interest' (with the same percentage scale for each item).

Severity of Consequences: In each scenario, respondents were asked for the severity of the possible consequences (Grasmick \& Bursik, 1990): 'Look at these legal consequences again. How much of a problem would they be for you? (a) ... (b) ... (c) ...' $(1=$ no problem, 2 = a small problem, $3=$ a medium problem, $4=$ a large problem .

A factor analysis with Varimax rotation for all deterrence items confirmed the differentiation between the three sub-concepts. It yielded a three-factor solution (Eigenvalues of 5.50, 3.70, and 1.03, respectively) that explained $73 \%$ of the variance. The two Probability of Detection items from the two scenarios loaded on one factor (explaining $11 \%$ of variance after rotation), the six Probability of Consequences items loaded on a second factor (explaining 29\% of variance), and the six Severity items loaded on a third factor (explaining $32 \%$ of variance). All these factor loadings were greater than 0.72 , while there were no substantial cross-loadings (max. 0.30). As a consequence, item scores were averaged to obtain measures of Probability of Detection $(\alpha=0.67)$, Probability of Consequences $(\alpha=0.91)$, and Severity of Consequences $(\alpha=0.94)$.

\section{Inclusive Identification}

Two items measured identification with Australians (see Haslam, 2001), which should approximate the group to which the perceived social norms (see below) might be attributed: 'Being a member of the Australian community is important to me', and 'I feel a 
sense of pride in being a member of the Australian community' $(1=$ do not agree at all, 7 $=$ agree completely). Scores were averaged to obtain a measure of Inclusive Identification $(\alpha=0.93)$. However, the measure was highly skewed and truncated at the pole of high identification; $63 \%$ of respondents had a score of $6,6.5$, or $7(M d n=6, M=5.83)$. A large portion of the variance in inclusive identification would thus be located at the high identification end of the scale, which would be inappropriate for tests of predictions about the impact of a high versus low degree of inclusive identification. Therefore, the measure was dichotomised, with scores lower than or equal to the midpoint of the scale (4) defined as low identification $(n=157)$ and scores greater than the midpoint of the scale defined as high identification $(n=1150){ }^{1}$

\section{Norms}

Social Norms: The social norms referred to the perceived prescriptive norms of 'most people' and were measured by three items $(1=$ no!!, $5=$ yes!! $)$ : 'Do MOST PEOPLE think they should honestly declare cash earnings on their tax return?'; 'Do MOST PEOPLE think it is acceptable to overstate tax deductions on their tax return?' (reverse-coded); and 'Do MOST PEOPLE think working for cash-in-hand payments without paying tax is a trivial offence?' (reverse-coded). Scores were averaged to obtain a measure of Social Norms $(\alpha=0.60)$.

Personal Norms: The personal norms referred to one's own prescriptive norms concerning taxpaying and were measured by the equivalent three items $(1=$ no!!, $5=$ yes!!): 'Do YOU think you should honestly declare cash earnings on your tax return?'; 'Do YOU think it is acceptable to overstate tax deductions on your tax return?' (reverse-coded); and 'Do YOU think working for cash-in-hand payments without paying tax is a trivial offence?' (reversecoded). Scores were averaged to obtain a measure of Personal Norms $(\alpha=0.58)$.

\footnotetext{
${ }^{1}$ Dichotomisation of variables is often criticised for loss of information. The reason for using the procedure in the present context may be conceived of as focusing on the relevant information, given the empirical peculiarities of the variable. It is less relevant whether respondents indicated scale points 6 or 7 for their degree of identification (this might rather reflect some personal preference for extreme or less extreme responses); more meaningful and important is whether respondents tended towards the one or the other end of the identification scale. However, variance in this respect would be diluted by the variance of a large number of cases at the upper end of the scale, if the original scale would be used (Wenzel, 2002a).
} 
A factor analysis with Varimax rotation for the six norm items confirmed the conceptual distinction between personal and social norms. It yielded a two-factor solution (Eigenvalues of 1.86 and 1.46, respectively) which explained $55 \%$ of the variance. All social norm items loaded on one factor, and all personal norm items loaded on the other factor (with factor loadings greater than 0.65 and no substantial cross-loadings).

\section{Results}

Predictions were tested by hierarchical regression analyses. First, Hypotheses 1 to 4 were tested for the three forms of tax compliance separately. Step 1 of the analyses controlled for background variables Sex, Age and Personal Income. Findings for these variables will not be reported in the present paper, as they have already been reported and discussed elsewhere (Wenzel, 2002a). In Step 2, main effects of the three deterrence variables and the two norm variables were tested, being entered in the regression analyses using the 'enter' method, as they needed to be controlled when testing for interaction effects. Interaction terms were introduced in Step 3 using the 'stepwise' method (with entry and removal criteria of $\mathrm{p}<0.10$ and $\mathrm{p}>0.20$, respectively). Given the high number of interaction terms, this method reduced the problem of multicollinearity and kept the focus on relevant interaction terms. Second, Hypothesis 5 required a more complex model including tests for three-way interactions with Identification as well as all implied two-way interactions. Due to space limitations, only results for the summary variable Tax Evasion will here be reported. In all analyses, variables were standardised before building product terms to reduce the risk of multicollinearity and obtain appropriate standardised coefficients for the interactions (Aiken \& West, 1991). 
Table 1. Hierarchical regression analyses for three taxpaying behaviours

\begin{tabular}{|c|c|c|c|c|c|c|}
\hline \multirow{2}{*}{ Predictor } & \multicolumn{2}{|c|}{ Pay Income } & \multicolumn{2}{|c|}{ Non-Pay Income } & \multicolumn{2}{|c|}{ Deductions } \\
\hline & Step $2(\beta)$ & Step $3(\beta)$ & Step $2(\beta)$ & Step $3(\beta)$ & Step $2(\beta)$ & Step $3(\beta)$ \\
\hline Prob. of Detection & $-0.10^{* * *}$ & $-0.11^{k * * *}$ & 0.01 & 0.01 & $-0.06^{\dagger}$ & $-0.06 *$ \\
\hline Prob. of Consequences & -0.03 & -0.04 & -0.04 & -0.04 & -0.04 & -0.04 \\
\hline Sanction Severity & -0.05 & $-0.05^{\dagger}$ & $-0.11^{* * *}$ & $-0.11^{* * *}$ & $-0.09^{* * *}$ & $-0.09^{* *}$ \\
\hline Personal Norm & $-0.18^{* * *}$ & $-0.17^{* * *}$ & $-0.10^{* * *}$ & $-0.10^{* * *}$ & $-0.19^{* * *}$ & $-0.19^{* * *}$ \\
\hline Social Norm & 0.02 & 0.02 & $0.06^{*}$ & $0.06^{*}$ & 0.02 & 0.02 \\
\hline Pers. N.XDetection & & $0.06^{* *}$ & & ---- & & ---- \\
\hline Pers. N.X Consequences & & ---- & & ---- & & ---- \\
\hline Pers. N.XSeverity & & --- & & $0.06^{*}$ & & $0.05^{*}$ \\
\hline Soc. N.XDetection & & ---- & & ---- & & ---- \\
\hline Soc. N.X Consequences & & ---- & & ---- & & ---- \\
\hline Soc. N.XSeverity & & $-0.07^{* *}$ & & $-0.14^{* * *}$ & & $-0.06^{*}$ \\
\hline (Constant) & -0.01 & -0.02 & -0.01 & -0.01 & -0.03 & -0.04 \\
\hline$R^{2}$ & 0.096 & 0.105 & 0.036 & 0.058 & 0.082 & 0.088 \\
\hline$R^{2}$ change & 0.096 & 0.009 & 0.036 & 0.022 & 0.082 & 0.006 \\
\hline Fchange & $18.38^{* * *}$ & $6.87^{* *}$ & $6.27^{* * * *}$ & $15.58^{* * *}$ & $15.52^{* * *}$ & $4.22^{*}$ \\
\hline$d f$ & 8,1390 & 2,1388 & 8,1347 & 2,1345 & 8,1388 & 2,1386 \\
\hline
\end{tabular}

Note. ${ }^{\dagger} p<0.10,{ }^{*} p<0.05,{ }^{* *} p<0.01,{ }^{* * *} p<0.001$ (two-tailed). 


\section{Norms and Forms of Tax Evasion}

The regression findings for the three forms of tax noncompliance are summarised in Table 1. The findings reveal some parallels and differences between the three taxpaying behaviours. Let us consider the main effects of deterrence variables first. For Pay Income , there was only a significant effect of Probability of Detection, being negatively related to noncompliance, as predicted. In contrast, for Non-Pay Income, Sanction Severity was the only deterrence variable that was significantly negatively related to noncompliance. For Deductions, there were significant negative relationships for Sanction Severity and Probability of Detection, but the latter was only significant after inclusion of interaction terms and thus rather unreliable. Probability of Consequences had no independent effect for any of the three forms of tax evasion. Overall, in line with Hypothesis 1, there were deterrence effects for all three forms of noncompliance; however, which element of deterrence carried this effect varied between taxpaying behaviours.

Regarding Personal and Social Norms, the findings were more consistent. For all three behaviours, there was a significant negative relationship between Personal Norms of tax honesty and tax noncompliance, as predicted in Hypothesis 2. In contrast, Social Norms had no favourable effects when Personal Norms were controlled. In fact, there was even a significant positive relationship between Social Norms and underreporting of Non-Pay Income.

In all three cases of tax evasion, interaction terms contributed significantly to the explanation of variance. For Pay Income, Personal Norms significantly moderated the effect of Detection Probability. Figure 1a depicts the results of simple slope analyses clarifying the interaction. All simple slopes for one interacting variable were calculated for levels of -1 and +1 standard deviation of the other variable of the interaction (Aiken \& West, 1991). 
(a)

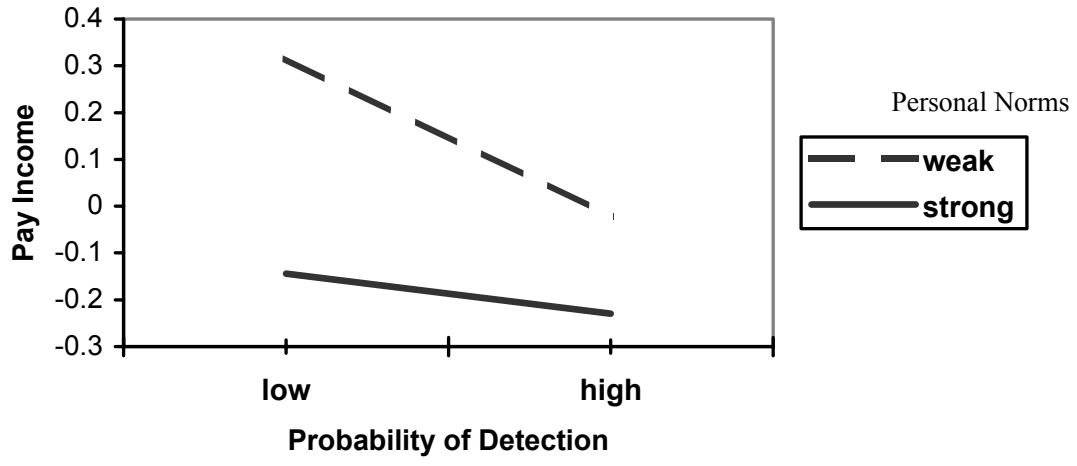

(b)

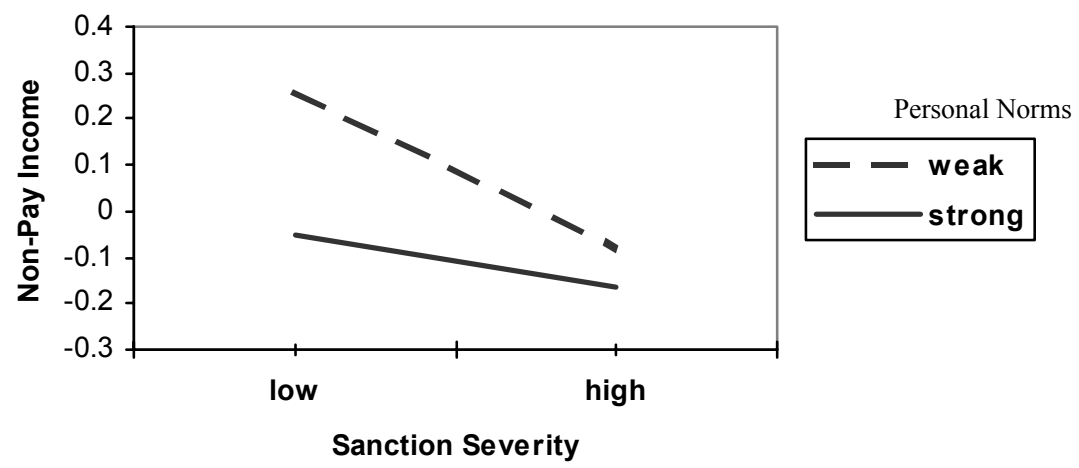

(c)

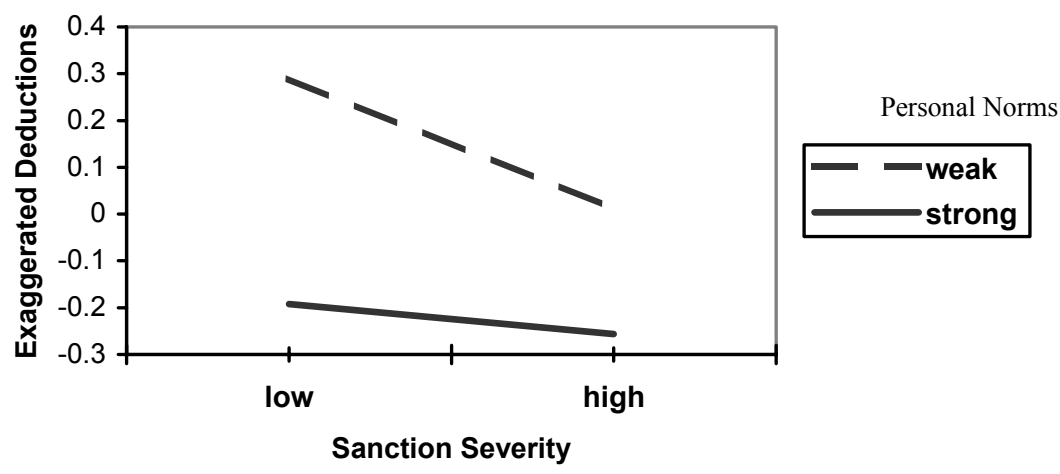

Figure 1. Simple slopes at low and high levels of Personal Norms, for effects on (a) Pay Income Underreporting, (b) Non-Pay Income Underreporting, and (c) Exaggerating Deductions

When there were weak Personal Norms of tax honesty, Detection Probability was significantly negatively related to the underreporting of Pay Income $(\beta=-0.17, p<0.001)$. When there were strong Personal Norms of tax honesty, however, Detection Probability had no significant effect $(\beta=-0.04, n s)$. These results are consistent with Hypothesis 3; 
however, the predicted moderation effect of Personal Norms only occurred for one of the deterrence variables, notably for the variable that also had significant main effects. In this sense, the findings are consistent across all three forms of tax evasion. Namely, Personal Norms also moderated significantly the relationship between Sanction Severity and underreporting of Non-Pay Income, which, as reported before, was the only significant deterrence effect in this case. Simple slope analyses (see Figure 1b) confirmed that Sanction Severity was only significantly negatively related to underreporting of Non-Pay Income when Personal Norms of tax honesty were weak $(\beta=-0.17, p<0.001)$, but not when Personal Norms were strong $(\beta=-0.06, n s)$. Likewise, Personal Norms moderated the relationship between Sanction Severity and exaggeration of Deductions, which, again, had been the only reliable main effect. Again, simple slope analyses showed (see Figure 1c) that Sanction Severity was significantly negatively related to false Deduction claims when Personal Norms of tax honesty were weak $(\beta=-0.14, p<0.001)$, but not when they were strong $(\beta=-0.03, n s)$.

Moreover, there were significant interaction effects involving Social Norms that were consistent over all three taxpaying behaviours for Sanction Severity. The three sets of simple slope analyses illuminating these interaction effects are depicted in Figure 2. First (see Figure 2a), when there were weak Social Norms of tax honesty, Sanction Severity was not significantly related to the underreporting of Pay Income $(\beta=0.03, n s)$. However, there was a significant negative relationship consistent with a deterrence effect when Social Norms of tax honesty were perceived to be strong $(\beta=-0.12, p=0.002)$. These results supported Hypothesis 4, and similar patterns were found for the other two forms of tax evasion. Namely (see Figure 2b), Sanction Severity was not significantly related to the underreporting of Non-Pay Income when Social Norms of tax honesty were weak $(\beta=$ $0.03, n s)$, but there was a significant negative relationship when Social Norms were strong $(\beta=-0.26, p<0.001)$. Similarly, there was apparently no deterrence effect of Sanction Severity on Deductions when Social Norms were weak $(\beta=-0.03, n s)$, but there was a significant negative effect when Social Norms were perceived to be strongly against tax evasion $(\beta=-0.15, p<0.001)$. 
(a)

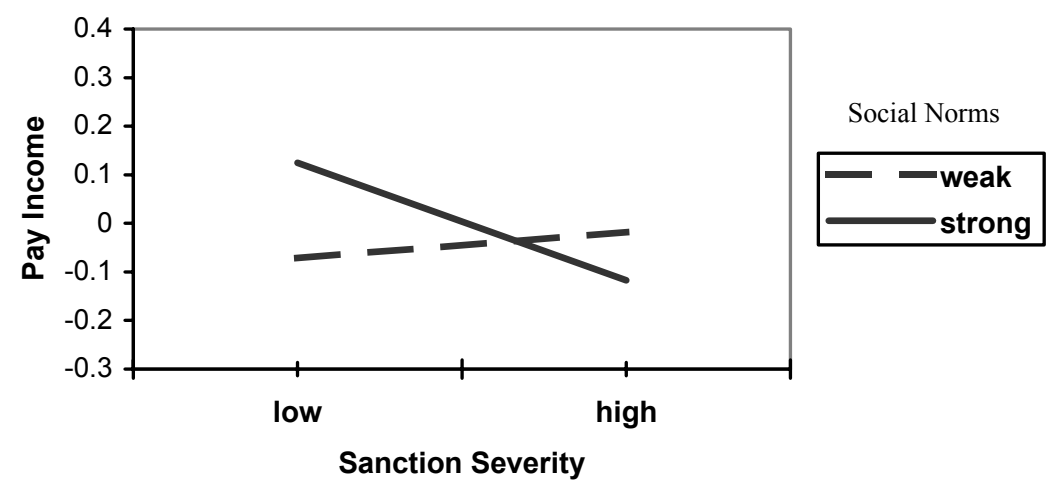

(b)

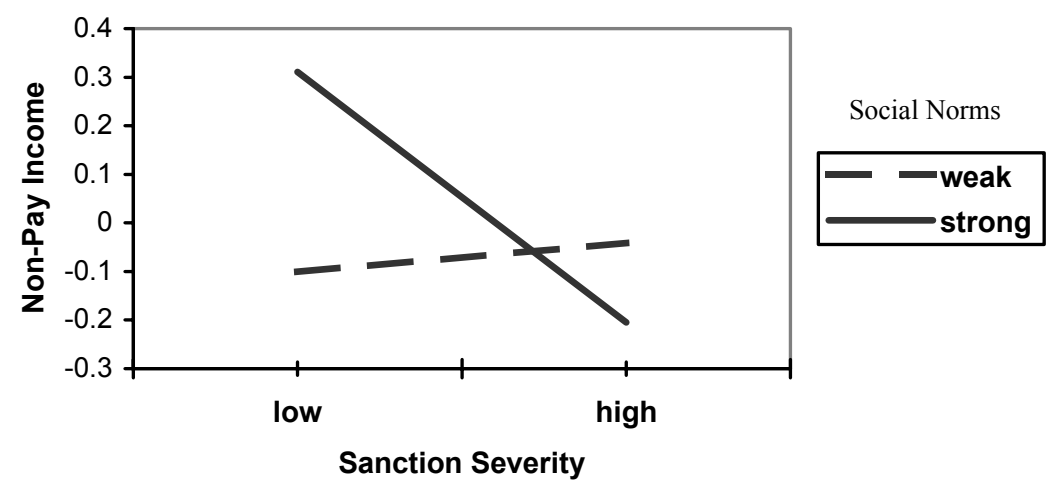

(c)

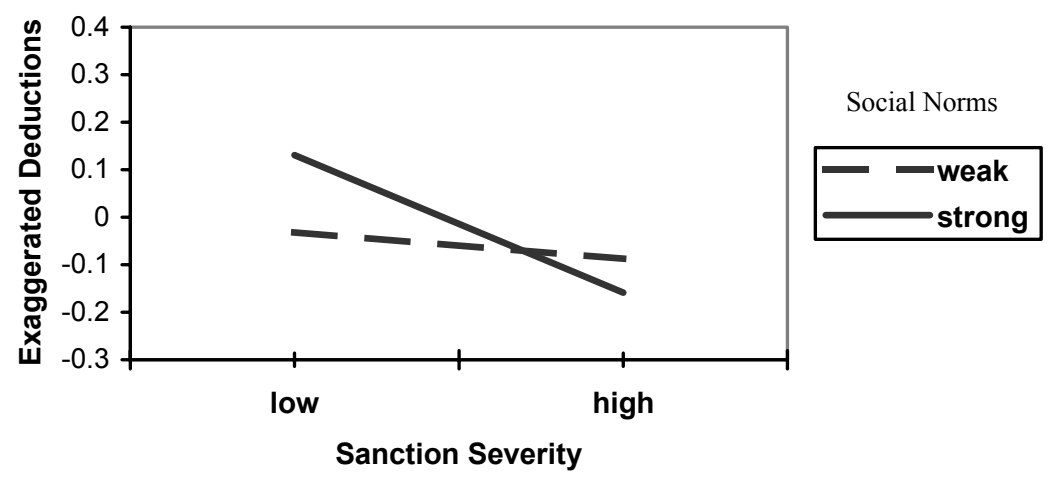

Figure 2. Simple slopes at low and high levels of Social Norms, for effects on (a) Pay Income Underreporting, (b) Non-Pay Income Underreporting, and (c) Exaggerating Deductions.

To sum up, there was supportive evidence for all four hypotheses, however only for selected elements of the deterrence construct. Personal Norms appeared to have moderating effects on those deterrence variables that also had unmoderated relationships to tax evasion. In contrast, Social Norms moderated the effects of Sanction Severity only. 


\section{Identification and Social Norms of Tax Evasion}

To test the whole set of predictions, including Hypothesis 5, I will now turn to the summary variable Tax Evasion. Equivalent analyses with the separate forms of tax evasion as dependent variables yielded very similar results and need not be detailed here. Hypothesis 5 predicted that Identification would further moderate the two-way interactions between Social Norms and deterrence variables. Therefore, in a further step of the regression, all six three-way interactions between Identification, either Social Norms or Personal Norms, and either of the three deterrence variables were entered. As a consequence, all two-way interactions implied by the three-way interaction and the main effect of identification had to be included, in addition to the predictors considered in the previous analyses (Aiken \& West, 1991). Again, two-way and three-way interactions were entered using the 'stepwise' function in order to reduce the model to the empirically necessary elements and thus avoid undue complexity and the risk of multicollinearity.

The findings are summarised in Table 2. First, there was only a significant main effect of Sanction Severity, while the effect of Detection Probability was more unreliable; it was marginally significant in Step 1 and became only significant when interactions were included. These results mirrored the findings from the earlier analyses for the different taxpaying behaviours. Likewise, the significant negative relationship between Personal Norms and Tax Evasion was consistent with the earlier analyses, while Social Norms again had no significant effect. Further, the analysis produced three two-way interactions that were reliable over all three steps (the Identification by Social Norms interaction was only significant at Step 2 and will not be discussed). First, the Personal Norm by Sanction Severity interaction replicated the earlier findings, showing that Severity had a stronger negative relationship (interpretable as a deterrence effect) when Personal Norms were weak. Second, the Social Norm by Sanction Severity interaction was also consistent with the earlier results; Severity had a stronger negative relationship (and thus possible deterrence effect), when Social Norms were strong. Third, the Identification by Sanction Severity interaction suggests a stronger deterrence effect for perceived Severity when respondents identified with their national group to a lesser degree. 
The latter two interaction effects, however, have to be considered in the context of the significant three-way interaction effect of Identification, Social Norm, and Sanction Severity. To clarify the meaning of this interaction, Figure 3 shows simple slopes of Sanction Severity for low versus high levels of Identification and Social Norms. The only significant relationship emerged for low levels of Identification and strong Social Norms of tax honesty $(\beta=-0.35, p<0.001)$. For the other combinations of levels of Identification and Social Norms, Sanction Severity was not significantly related to Tax Evasion (Identification low, Social Norms low: $\beta=0.04, n s$; Identification high, Social Norms low: $-0.03, n s$; Identification high, Social Norms high: $\beta=-0.07, n s)$. The results were in line with Hypothesis 5. Specifically, Sanction Severity was only negatively related to Tax Evasion, and seemed to have a deterrence effect, when norms of tax honesty were

Table 2. Hierarchical regression analysis for tax evasion

\begin{tabular}{lccc}
\hline Predictor & Step 1 $(\beta)$ & Step 2 $(\beta)$ & Step 3 $(\beta)$ \\
\hline Prob. of Detection & $-0.05^{\dagger}$ & $-0.07^{*}$ & $-0.07^{*}$ \\
Prob. of Consequences & -0.05 & -0.04 & -0.04 \\
Sanction Severity & $-0.12^{* * *}$ & $-0.11^{* * *}$ & $-0.10^{* * *}$ \\
Personal Norm & $-0.20^{* * *}$ & $-0.20^{* * *}$ & $-0.20^{* * *}$ \\
Social Norm & 0.04 & 0.04 & 0.03 \\
Identification & $-0.06^{*}$ & $-0.06^{*}$ & $-0.05^{\dagger}$ \\
Pers. N.XSeverity & & $0.05^{*}$ & $0.07^{* *}$ \\
Soc. N.XSeverity & & $-0.12^{* * *}$ & $-0.11^{* * *}$ \\
Ident.XSeverity & & $0.05^{*}$ & $0.05^{*}$ \\
Ident.XSoc. N. & & $-0.06^{*}$ & -0.04 \\
Ident.XSoc. N.XSeverity & & & $0.09^{* * *}$ \\
\multicolumn{1}{c}{ (Constant) } & -0.02 & -0.03 & -0.03 \\
\hline$R^{2}$ & 0.114 & 0.138 & 0.149 \\
$R^{2}$ change & 0.114 & 0.024 & 0.011 \\
$F$ change & $18.63^{* * *}$ & $8.92^{* * *}$ & $16.13^{* * *}$ \\
$d f$ & 9,1297 & 4,1293 & 1,1292
\end{tabular}

Note. For steps 2 and 3 the stepwise method was used; only predictors included in the regression model are listed here. ${ }^{\dagger} p<0.10,{ }^{*} p<0.05,{ }^{* *} p<0.01,{ }^{* * * *} p<0.001$ (two-tailed). 
(a) Low Levels of Identification

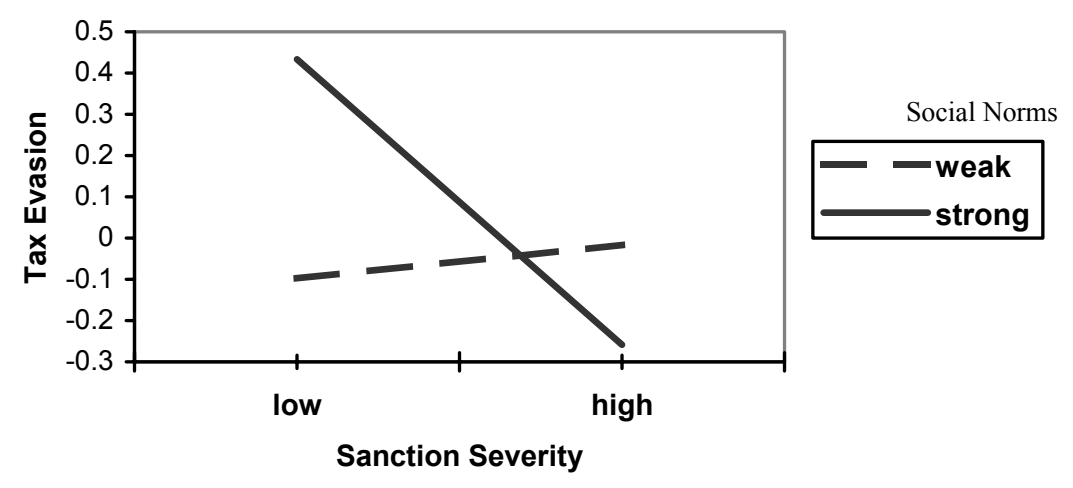

(b) High Levels of Identification

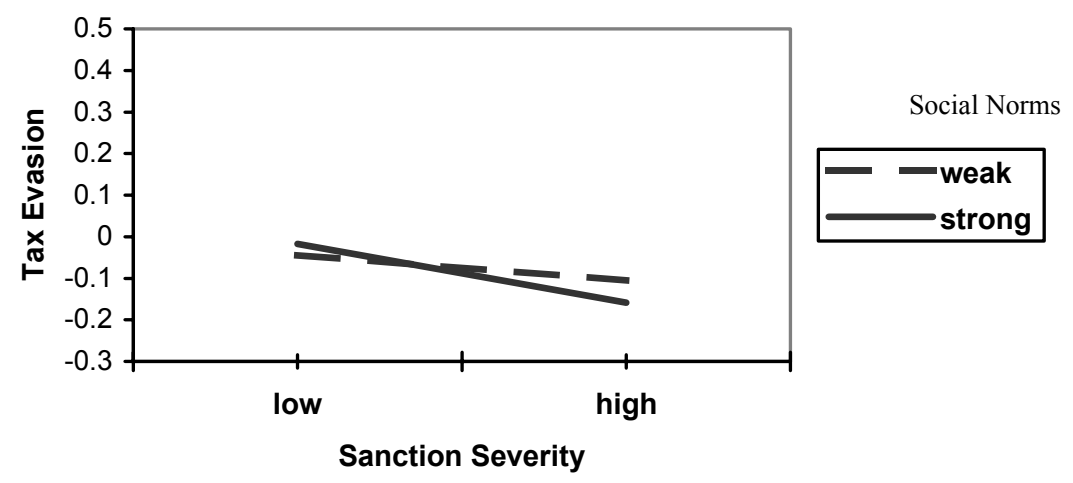

Figure 3. Simple slopes at low and high levels of Identification as well as Social Norms, for effects of Sanction Severity on Tax Evasion.

perceived as strong, but where the norms were not internalised or incorporated into one's social self through a process of social identification.

\section{Discussion}

The findings of this study were overall consistent with my theoretical predictions concerning the relevance of norms for the deterring effects of legal sanctions against tax evasion. While I distinguished between three deterrence components, there were no $a$ priori expectations about their relative importance. Previous research had shown more consistent evidence for the deterring effects of detection probability (for example, Varma \& Doob, 1998), so that it was somewhat surprising that perceived severity of sanctions was 
in the present study, on the whole, more important than perceived probability of detection or its consequences. ${ }^{2}$ It is not quite clear why severity of sanctions was the more potent element in the present study. However, the measure used here followed Grasmick and Bryjak's (1980) research, where the variable had significant effects, and tapped into the subjective severity of consequences. Other studies often operationalised severity as the perceived likelihood of objective consequences, such as penalty levels (for example, Varma \& Doob, 1998), without acknowledging that the meaning of the penalties could differ between people (see Williams \& Hawkins, 1986). Note that the latter operationalisation is similar to the measure of probability of consequences that had no effects in the present study. Another question that cannot be resolved here is why, for underreporting of pay income, detection probability was more important than severity of sanctions, while the opposite was the case for underreporting of non-pay income and deduction claims.

However, abstracting from the content of the deterrence factors, the results are very much in line with the theoretical predictions. First, there were deterrence effects on all the compliance measures (even if the driving deterrence factor varied). Second, personal norms, or individual morality, were significantly related to one's self-reported taxpaying behaviour, whereas social norms, once personal norms were controlled, had no favourable effects on tax compliance. Third, personal norms significantly moderated the effect of the 'driving' deterrence factor: there was only a deterrence effect when individual morality was rather lax and, we might say, did not exclude tax evasion from one's behavioural options. Fourth, social norms significantly moderated the effects of sanction severity: there was only a deterrence effect when social norms were perceived as being strongly opposed to tax evasion. Fifth, this moderating effect of social norms on the deterrent effects of sanction severity held only for respondents who did not identify with their nation. These findings were consistent across three different forms of tax compliance and their summary variable.

\footnotetext{
${ }^{2}$ It may be of interest that further analyses showed no empirical support for a multiplicative model of deterrence effects (see also Carroll, 1987). Regressing the variable Tax Evasion on deterrence, norm, identification, and control variables in Step 1, the two-way interactions between deterrence variables in Step 2, and the three-way interaction in Step 3, interactions were altogether either not significant or even against
} 
The findings for the role of personal norms replicated previous evidence in the area of tax compliance (as well as other delinquent acts). The main effect of personal norms is consistent with evidence that individual morality, in and of itself, is a strong determinant of taxpaying behaviour (Bosco \& Mittone, 1997; Grasmick \& Bursik, 1990; Hasseldine \& Kaplan, 1992; Kaplan \& Reckers, 1985; Reckers et al., 1994; Schwartz \& Orleans, 1967). The effect of personal norms moderating the impact of deterrence variables has also previously been shown in the area of tax compliance (Smith, 1990; see also Reckers et al., 1994) as well as other offences (Bachman et al., 1992; Burkett \& Ward, 1993; Paternoster \& Simpson, 1996; Simpson, 2002). Personal norms against tax evasion have a strong impact on taxpaying behaviour, to an extent that they can render considerations of possible negative (or positive) consequences, such as legal sanctions, irrelevant to the individual. Personal norms represent one's individual ethics in which one sincerely believes and which one truly values. Of course, these are not asocial norms at which one arrives in a process of purely intraindividual deliberation. Rather, these ethical views develop in the course of one's life-long socialisation. For instance, they are the views of the social groups with which one identifies; through identification the group becomes part of one's social self and one feels committed to its norms and values (Turner, 1991). Any suggestion that one might behave in contradiction to these internalised norms would threaten one's self, one's identity as a member of that group, and the values that defines one's group identity.

However, the more distinctive contribution of the present study is its demonstration of a reverse moderation effect for social norms that are not reflected in one's personal norms and not internalised due to a disassociation, or disidentification, from the group to which they are attributed. Specifically, there was no main effect of social norms when personal norms were controlled. This indicates that social norms in and of themselves do not influence taxpaying behaviour unless they are considered one's own norms, internalised in one's self through a process of identification with the group holding the norms (Wenzel, 2002b). However, perceived social norms moderated the impact of sanction severity on tax compliance. Perceived severity of sanctions had a stronger, and in fact only a significant, negative relationship to tax evasion when social norms were perceived to be strongly

predictions. The latter probably reflected suppression effects, and thus our focus on main effects seemed fully warranted. 
opposed to tax evasion. This finding is consistent with Williams and Hawkins' (1986) proposition of a deterrence effect that operates through its implied social costs, as well as earlier contentions by Zimring and Hawkins (1971) or Tittle and Logan (1973; p. 386) that 'formal sanctions can be effective only if reinforced by informal sanctions'.

Hence, while there was evidence that strong personal norms reduce the impact of deterrence variables, strong social norms can increase their effects. These effects thus need to be separated statistically to make them apparent, and distinguished analytically to understand them. I contend that the social norm moderation effect is based on norms that are not internalised and incorporated in one's own ethical make-up. The further moderation of this effect by levels of identification with the group to which the norms are attributed confirms this contention. Social norms moderated the deterrence effect of sanction severity only when respondents indicated a low level of identification with their national group. Being less identified with their group, people should be less likely to internalise its norms (a commitment that would make deterrence rather irrelevant). Rather, they should consider the social norms as external to them, but nonetheless a social reality that can effect the social meaning of sanctions they would face for acts of tax evasion.

These results are consistent with findings by Pate and Hamilton (1992) as well as Sherman et al. (1992) for the effects of specific deterrence; that is effects of actually receiving punishments on future behaviour and recidivism. Rather than perceived strength of social norms, these authors investigated the moderating effects of the offenders' employment and marital status, and thus presumably the relevance of social norms for their future outcomes. The results showed that arrests for spouse assault reduced recidivism only for offenders who were employed and married, that is, for whom public opinion would have more severe consequences. The present study, however, sheds some light on a confusion in Sherman et al.'s (1992) article. The authors concluded that their study yielded evidence that informal sanctions condition and reinforce effects of formal sanctions, whereas the results did not support the alternative notion that informal control replaces social sanctions and makes them irrelevant. My research shows that, in fact, both processes may hold true, but the underlying processes need to be differentiated. When internalised, norms can indeed render a deterrence cost-benefit analysis irrelevant; however, norms external to self 
can impact on the cost-benefit analysis and thus enhance the deterrent effects of legal sanctions. $^{3}$

However, how exactly do social norms impact on the costs of legal sanctions? This study did not investigate the intervening processes, so I can only speculate about possible answers. We learned, however, that the social norm effects, indicating socially mediated deterrence, were restricted to respondents who did not strongly identify with their national group. First, it could be that social norms, measured in this study as what one think most people think about evading tax, constitute a 'majoritarian morality' (Braithwaite, 1989) to which one is subjected based on one's minimal inclusion in the group of people, even if one does not identify with them. People can choose to be uncommitted to, reject, or violate social norms and rules, however they can hardly escape the fact that most others will evaluate them by these norms and rules. A perceived strong moral consensus against tax evasion, for instance, becomes a social reality that implies negative evaluation, loss of status and esteem, if one is convicted of evading tax. ${ }^{4}$ Second, the minimal degree of inclusion may be conceived as interdependence where one's own outcomes are dependent on other people's behaviours. The power of majorities lies then not only in their nearconsensual negative evaluation of offenders, but also in the material consequences it implies. Majorities have the numbers; they hold positions at most pivots of society and may decide over the fate and outcomes of the offender.

In either case the social norm effect would be due to the realisation that social norms are a social reality that one can hardly escape. Deterrence does not occur in a social vacuum. Legal sanctions and the threats they impose on people have a social origin and social meaning. In fact, however, we saw that norms can both limit and boost the effects of deterrence. When internalised as part of one's own moral standards, norms make

\footnotetext{
${ }^{3}$ It should be added that, while we found no deterrence effect when social norms were considered tolerant of tax evasion, Pate and Hamilton (1992) and Sherman et al. (1992) found a counterproductive effect of arrests when offenders were unemployed and unmarried. A possible reason is that their study investigated effects of specific deterrence and actual sanctions that are more likely to elicit reactance than general deterrence and the mere prospect of a punishment are.

${ }^{4}$ This would seem true unless one takes on an identity as a tax evader and actively tries to reverse the meaning of social norms and values. In this case, social norms could produce reactance and the evaluative threat could reinforce one's subcultural identity and criminal career, in line with the argument of labelling theorists (for example, Tannenbaum, 1938).
} 
deterrence superfluous. People would comply because they think it is right. The mechanism corresponds to a process of 'reintegrative shaming' (Braithwaite, 1989) where norms induce shame for one's offence (or, temptation to offend), because one is made feel included in the community and thus endorses the norms it represents. In contrast, when considered external to one's self, norms can make deterrence more powerful. People would comply because they think they would lose otherwise. They would lose respect, reputation, and opportunities, as a consequence of their 'stigmatisation' (Braithwaite, 1989) by the majority. It would seem that, whatever the degree of internalisation of the norms, norms have a positive effect on compliance. However, I would posit as a hypothesis for future work that in the case of external norms causing 'stigmatisation', offenders or would-be offenders might also lose respect for the majority and confine themselves to the normative frame of reference of their criminal subgroup.

The present research certainly has some limitations. Most importantly, the data were of a correlational nature and therefore do not warrant causal interpretations. Wherever I discussed findings in terms that suggested a causal interpretation, this should be considered as testing for consistency with a causal prediction, but where causality cannot be inferred from the data. Specifically, for deterrence effects a reversed causal influence is quite possible, with perceptions of deterrence variables being used to rationalise one's behaviour and present oneself as rational and consistent (Hessing et al., 1992). Moreover, the present study measured self-reported past compliance but current perceptions of deterrence variables. This has been criticised as actually reversing the temporal sequence, and prospective compliance measures have been suggested as a better solution for crosssectional designs (Grasmick \& Bursik, 1990; Williams \& Hawkins, 1986). However, it is unclear whether people's predictions of their future behaviour are as reliable as their reports on past behaviour.

Certainly, a strength of the present research is the consistency of results across a variety of tax compliance forms and measures. This warrants some confidence in the reliability of the findings, which should stimulate further research into the social determination of deterrence effects. Policymakers might be excused for despairing at the complexity of the world of interaction effects that emerge in these analyses. However, if the theoretical 
interpretations emerging in these data were confirmed as robust by further research, they might imply a simple enough policy:

(a) nurture personal norms of honesty because these are the main game of tax integrity;

(b) secure deterrence because this works when personal norms fail;

(c) because of (a) and (b), presumptively order regulatory strategy so as to try for the greater power of personal norms first, falling back on deterrence when personal norms fail (Braithwaite, 2002);

(d) build strong identification with one's community and strong communitarian norms because these not only supply the process for building personal norms but also bolster deterrence when norms fail.

Tax compliance comes from high integrity individuals in a high integrity community that gives people an identity they value. Yet in addition the state must keep faith with high integrity citizens by deterring those with low integrity who do not pay their share. The normative implications, therefore, may not be as complex as the explanatory mechanisms that underpin them. 


\section{REFERENCES}

Aiken, L. S., \& West, S. G. (1991). Multiple regression: Testing and interpreting interactions. Newbury Park, CA: Sage.

Allingham, M. G., \& Sandmo, A. (1972). Income tax evasion: A theoretical analysis. Journal of Public Economics, 1, 323-338.

Alm, J., McClelland, G. H., \& Schulze, W. D. (1992). Why do people pay taxes? Journal of Public Economics, 48, 21-38.

Alm, J., McClelland, G. H., \& Schulze, W. D. (1999). Changing the social norm of tax compliance by voting. Kyklos, 52, 141-171.

Alm, J., Sanchez, I., \& DeJuan, A. (1995). Economic and noneconomic factors in tax compliance. Kyklos, 48, 3-18.

Andenaes, J. (1974). Punishment and deterrence. Ann Arbor, MI: University of Michigan Press.

Andreoni, J., Erard, B., \& Feinstein, J. (1998). Tax compliance. Journal of Economic Literature, 36(2), 818-860.

Bachman, R., Paternoster, R., \& Ward, S. (1992). The rationality of sexual offending: Testing a deterrence/rational choice conception of sexual assault. Law and Society Review, 26, 343-372.

Bosco, L., \& Mittone, L. (1997). Tax evasion and moral constraints: Some experimental evidence. Kyklos, 50(Fasc 3), 297-324.

Braithwaite, J. (1989). Crime, shame, and reintegration. Cambridge: Cambridge University Press.

Braithwaite, J. (2002). Restorative justice and responsive regulation. New York: Oxford University Press. 
Braithwaite, V. (2000). The Community Hopes, Fears and Actions Survey. Canberra: Centre for Tax System Integrity, Research School of Social Sciences, The Australian National University.

Burkett, S. R., \& Ward, D. A. (1993). A note on perceptual deterrence, religiously based moral condemnation, and social control. Criminology, 31(1), 119-134.

Carroll, J. S. (1978). A psychological approach to deterrence: The evaluation of crime opportunities. Journal of Personality and Social Psychology, 36, 1512-1520.

Carroll, J. S. (1987). Compliance with the law: A decision-making approach to taxpaying. Law and Human Behavior, 11, 319-335.

Cowell, F. A. (1992). Tax evasion and inequity. Journal of Economic Psychology, 13(4), $521-543$.

De Juan, A., Lasheras, M. A., \& Mayo, R. (1994). Voluntary tax compliant behavior of Spanish income tax payers. Public Finance, 49, 90-105.

Dubin, J. A., Graetz, M. J., \& Wilde, L. L. (1987). Are we a nation of tax cheaters? New econometric evidence on tax compliance. The American Economic Review, 77(2), 240-245.

Dubin, J. A., \& Wilde, L. L. (1988). An empirical analysis of federal income tax auditing and compliance. National Tax Journal, 16, 61-74.

Elffers, H., Weigel, R. H., \& Hessing, D. J. (1987). The consequences of different strategies for measuring tax evasion behavior. Journal of Economic Psychology, 8, 311337.

Erard, B., \& Feinstein, J. S. (1994). The role of moral sentiments and audit perceptions in tax compliance. Public Finance, 49, 70-89.

Falkinger, J. (1995). Tax evasion, consumption of public goods and fairness. Journal of Economic Psychology, 16(1), 63-72. 
Fischer, C. M., Wartick, M., \& Mark, M. M. (1992). Detection probability and taxpayer compliance: A review of the literature. Journal of Accounting Literature, 11, 1-46.

Franzoni, L. A. (2000). Tax evasion and tax compliance. In B. Bouckaert \& G. DeGeest (Eds.), Encyclopedia of law and economics (Vol. 4, pp. 52-94). Cheltenham, UK: Elgar.

Friedland, N., Maital, S., \& Rutenberg, A. (1978). A simulation study of income tax evasion. Journal of Public Economics, 10, 107-116.

Gibbs, J. P. (1975). Crime, punishment, and deterrence. New York: Elsevier.

Grasmick, H. G., \& Bryjak, G. J. (1980). The deterrent effect of perceived severity of punishment. Social Forces, 59, 471-491.

Grasmick, H. G., \& Bursik Jr, R. J. (1990). Conscience, significant others, and rational choice: Extending the deterrence model. Law and Society Review, 24(3), 837-861.

Grasmick, H. G., \& Green, D. E. (1980). Legal punishment, social disapproval and internalization as inhibitors of illegal behavior. Journal of Criminal Law and Criminology, $71,325-335$.

Grasmick, H. G., \& Scott, W. J. (1982). Tax evasion and mechanisms of social control: A comparison with grand and petty theft. Journal of Economic Psychology, 2, 213-230.

Harcourt, B. E. (2000). After the "social meaning turn": Implications for research design and methods of proof in contemporary criminal law policy analysis. Law \& Society Review, 34(1), 179-211.

Haslam, S. A. (2001). Psychology in organizations: The social identity approach. London: Sage.

Hasseldine, J., \& Kaplan, S. E. (1992). The effect of different sanction communications on hypothetical taxpayer compliance: Policy implications from New Zealand. Public Finance, $47,45-60$. 
Hessing, D. J., Elffers, H., Robben, H. S. J., \& Webley, P. (1992). Does deterrence deter? Measuring the effect of deterrence on tax compliance in field studies and experimental studies. In J. Slemrod (Ed.), Why people pay taxes: Tax compliance and enforcement (pp. 291-305). Ann Arbor, MI: University of Michigan Press.

Kaplan, S. E., \& Reckers, P. M. J. (1985). A study of tax evasion judgments. National Tax Journal, 38, 97-102.

Kelman, H. C. (1958). Compliance, identification, and internalization: Three processes of attitude change. Journal of Conflict Resolution, 2, 51 - 60.

Kinsey, K. A., \& Grasmick, H. G. (1993). Did the tax reform act of 1986 improve compliance? Three studies of pre- and post-TRA compliance attitudes. Law \& Policy, 15, 239-325.

Mason, R., \& Calvin, L. D. (1978). A study of admitted income tax evasion. Law and Society, 13, 73-89.

McAdams, R. H. (1997). The origin, development, and regulation of norms. Michigan Law Review, 96, 338-433.

Mearns, M., \& Braithwaite, V. (2001). The Community Hopes, Fears and Actions Survey: Survey method, sample representativeness and data quality. Centre for Tax System Integrity Working Paper No. 4. Canberra: Australian National University.

Nagin, D. S., \& Paternoster, R. (1991). The preventive effects of the perceived risk of arrest: Testing an expanded conception of deterrence. Criminology, 29, 561-587.

Pate, A. M., \& Hamilton, E. E. (1992). Formal and informal deterrents to domestic violence: The Dade county spouse assault experiment. American Sociological Review, 57, 691-697.

Paternoster, R. (1987). The deterrent effect of the perceived certainty and severity of punishment: A review of the evidence and issues. Justice Quarterly, 4, 173-217. 
Paternoster, R., Saltzman, L. E., Waldo, G. P., \& Chiricos, T. G. (1983). Perceived risk and social control: Do sanctions really deter? Law and Society Review, 17, 457-479.

Paternoster, R., \& Simpson, S. S. (1996). Sanction threats and appeals to morality: Testing a rational choice model of corporate crime. Law and Society Review, 30, 549-583.

Reckers, P. M. J., Sanders, D. L., \& Roark, S. J. (1994). The influence of ethical attitudes on taxpayer compliance. National Tax Journal, 47, 825-36.

Schmölders, G. (1970). Survey research in public finance: A behavioural approach to fiscal theory. Public Finance, 25, 300-306.

Schwartz, R. D., \& Orleans, S. (1967). On legal sanctions. University of Chicago Law Review, 34, 274-300.

Scott, W. J., \& Grasmick, H. G. (1981). Deterrence and income tax cheating: Testing interaction hypotheses in utilitarian theories. Journal of Applied Behavioural Science, 17, $395-408$.

Sheffrin, S. M., \& Triest, R. K. (1992). Can brute deterrence backfire? Perceptions and attitudes in taxpayer compliance. In J. Slemrod (Ed.), Who pays taxes and why? Tax compliance and enforcement (pp. 193-218). Ann Arbor: University of Michigan Press.

Sherman, L. W., Smith, D. A., Schmidt, J. D., \& Rogan, D. P. (1992). Crime, punishment, and stake in conformity: Legal and informal control of domestic violence. American Sociological Review, 57, 680-690.

Simpson, S. S. (2002). Corporate crime, law, and social control. Cambridge, UK: Cambridge University Press.

Smith, K. W. (1990). Integrating three perspectives on noncompliance: A sequential decision model. Criminal Justice and Behavior, 17(3), 350-369.

Tannenbaum, F. (1938). Crime and the community. Boston: Ginn and Co. 
Tittle, C. R., \& Logan, C. H. (1973). Sanctions and deviance: Evidence and remaining questions. Law and Society Review, 7, 371-392.

Turner, J. C. (1987). A self-categorization theory. In J. C. Turner, M. A. Hogg, P. J. Oakes, S. D. Reicher, \& M. S. Wetherell (Eds.), Rediscovering the social group: A selfcategorization theory (pp. 42-67). Oxford: Blackwell.

Turner, J. C. (1991). Social influence. Buckingham, UK: Open University Press.

Varma, K. N., \& Doob, A. N. (1998). Deterring economic crimes: The case of tax evasion. Canadian Journal of Criminology, 40, 165-184.

Vogel, J. (1974). Taxation and public opinion in Sweden: An interpretation of recent survey data. National Tax Journal, 27, 499-513.

Wallschutzky, I. G. (1984). Possible causes of tax evasion. Journal of Economic Psychology, 5(4), 371-384.

Wallschutzky, I. G. (1996). Issues in research methods: With reference to income tax research. Unpublished manuscript, University of Newcastle, Australia.

Webley, P. (1987). Audit probabilities and tax evasion in a business simulation. Economics Letters, 25, 267-270.

Webley, P., \& Halstead, S. (1986). Tax evasion on the micro: Significant simulations or expedient experiments? The Journal of Interdisciplinary Economics, 1, 87-100.

Wenzel, M. (2002a). The impact of outcome orientation and justice concerns on tax compliance: The role of taxpayers' identity. Journal of Applied Psychology, 87, 629-645.

Wenzel, M. (2002b). An analysis of norm processes in tax compliance. Centre for Tax System Integrity Working Paper No. 33. Canberra: Australian National University.

Williams, K. R., \& Hawkins, R. (1986). Perceptual research on general deterrence: A critical review. Law and Society Review, 20, 545-572. 
Witte, A. D., \& Woodbury, D. F. (1985). The effect of tax laws and tax administration on tax compliance: The case of the U.S. individual income tax. National Tax Journal, 38, 113.

Zimring, F. E., \& Hawkins, G. J. (1971). The legal threat as an instrument of social change. Journal of Social Issues, 27, 33-48. 


\section{THE CENTRE FOR TAX SYSTEM INTEGRITY WORKING PAPERS}

No. 1. Braithwaite, V., \& Reinhart, M. The Taxpayers' Charter: Does the Australian Taxation Office comply and who benefits? December 2000.

No. 2. Braithwaite, V. The Community Hopes, Fears and Actions Survey: Goals and Measures. March 2001.

No. 3. Braithwaite, V., Reinhart, M., Mearns, M., \& Graham, R. Preliminary findings from the Community Hopes, Fears and Actions Survey. April 2001.

No. 4. Mearns, M., \& Braithwaite, V. The Community Hopes, Fears and Actions Survey: Survey method, sample representativeness and data quality. April 2001.

No. 5. Sakurai, Y., \& Braithwaite, V. Taxpayers' perceptions of the ideal tax adviser: Playing safe or saving dollars? May 2001.

No. 6. Wenzel, M. The impact of outcome orientation and justice concerns on tax compliance: The role of taxpayers' identity. June 2001.

No. 7. Wenzel, M. Misperceptions of social norms about tax compliance (1): A prestudy. June 2001.

No. 8. Wenzel, M. Misperceptions of social norms about tax compliance (2): A field-experiment. June 2001.

No. 9. Taylor, N. Taxpayers who complain about paying tax: What differentiates those who complain from those who don't? June 2001.

No. 10. Wenzel, M. Principles of procedural fairness in reminder letters and awareness of entitlements: A prestudy. June 2001.

No. 11. Taylor, N., \& Wenzel, M. The effects of different letter styles on reported rental income and rental deductions: An experimental approach. July 2001.

No. 12. Williams, R. Prosecuting non-lodgers: To persuade or punish? July 2001.

No. 13. Braithwaite, V. Tensions between the citizen taxpaying role and compliance practices. Forthcoming

No. 14. Taylor, N. Understanding taxpayer attitudes through understanding taxpayer identities. July 2001. 
No. 15. Shover, N., Job, J., \& Carroll, A. Organisational capacity for responsive regulation. August 2001.

No. 16. Tyler, T. R. Trust and law-abidingness: A proactive model of social regulation. August 2001.

No. 17. Genser, B. Corporate income taxation in the European Union: Current state and perspectives. August 2001.

No. 18. McBarnet, D. When compliance is not the solution but the problem: From changes in law to changes in attitude. August 2001.

No. 19. Schneider, F., Braithwaite, V., \& Reinhart, M. Individual behaviour in Australia's shadow economy: Facts, empirical findings and some mysteries. September 2001.

No. 20. Taylor, N., \& Wenzel, M. Comparing rental income and rental deductions for electronic versus paper lodgers: A follow-up investigation. November 2001.

No. 21. Braithwaite, J. Through the eyes of the advisers: A fresh look at tax compliance of high wealth individuals. September 2001.

No. 22. Braithwaite, J., Pittelkow, Y., \& Williams, R. Tax Compliance by the very wealthy: Red flags of risk. September 2001.

No. 23. Braithwaite, J., \& Williams, R. Meta risk management and tax system integrity. October 2001.

No. 24. Braithwaite, J., \& Wirth, A. Towards a framework for large business tax compliance. November 2001.

No. 25. Murphy, K., \& Sakurai, Y. Aggressive Tax Planning: Differentiating those playing the game from those who don't? October 2001.

No. 26. Morgan, S., \& Murphy, K. The 'Other Nation': Understanding rural taxpayers' attitudes toward the Australian tax system. December 2001

No. 27. Ahmed, E., \& Sakurai, Y. Small business individuals: What do we know and what do we need to know? December 2001.

No. 28. Hobson, K. Championing the compliance model: From common sense to common action. December 2001.

No. 29. Smart, M. The Under-30 taxpayer: Different from the rest? Forthcoming. 
No. 30. Job, J., \& Honaker, D. Short-term experience with responsive regulation in the Australian Taxation Office. May 2002.

No. 31. Frey, B. A constitution for knaves crowds out civic virtues. June 2002.

No. 32. Feld, L., \& Frey, B. Trust breeds trust: How taxpayers are treated. June 2002.

No. 33. Wenzel, M. An analysis of norm processes in tax compliance. July 2002.

No. 34. Wenzel, M. The social side of sanctions: Personal and social norms as moderators of deterrence. October 2002. 